\title{
A Mathematical Model for the Upper Limits of Thyroid Volume in Adolescents
}

Jacob Treanor

University of South Florida

\author{
Advisors: \\ Arcadii Grinshpan, Mathematics and Statistics \\ Randall Hamilton, Endocrine Oncology, Moffitt Cancer Center \\ Problem Suggested By: Randall Hamilton
}

Follow this and additional works at: https://digitalcommons.usf.edu/ujmm

Part of the Mathematics Commons

UJMM is an open access journal, free to authors and readers, and relies on your support:

Donate Now

\section{Recommended Citation}

Treanor, Jacob (2019) "A Mathematical Model for the Upper Limits of Thyroid Volume in Adolescents," Undergraduate Journal of Mathematical Modeling: One + Two: Vol. 9: Iss. 2, Article 6.

DOI: https://doi.org/10.5038/2326-3652.9.2.4905

Available at: https://digitalcommons.usf.edu/ujmm/vol9/iss2/6 


\title{
A Mathematical Model for the Upper Limits of Thyroid Volume in Adolescents
}

\begin{abstract}
This paper describes a mathematical model that relates age to the volume of the thyroid gland, given in milliliters, of adolescents based on data from a 1997 study by the World Health Organization (W.H.O.) (World Health Organization, 1997). Using the upper limit per age group provided by the data, a model was constructed through integration of the second derivative of the data for males and females, ages 6-15. It was concluded that the upper limit for the thyroid volume could be expressed by one of two second order polynomial equations, depending on gender, with any values significantly larger than those predicted by the model being potential indicators of hyperthyroidism.
\end{abstract}

\section{Keywords}

hyperthyroidism, adolescents, thyroid gland volume, polynomial approximation

\section{Creative Commons License}

(c) (i) ()

This work is licensed under a Creative Commons Attribution-Noncommercial-Share Alike 4.0 License. 


\section{PROBLEM STATEMENT}

As thyroid volume changes with age, making it difficult to diagnose hyperthyroidism in adolescents, developing a mathematical model that can be used to predict the upper limits of thyroid volume, based on a patient's age, can be a useful tool in the early detection of the disease.

\section{MOTIVATION}

Hyperthyroidism, or an overactive thyroid, is a disease in which the thyroid gland of the affected person secretes more thyroid hormone than normal, resulting in "nervousness, irritability, increased sweating, heart racing, hand tremors, anxiety, difficulty sleeping, thinning of [one's] skin, fine brittle hair and weakness in [one's] muscles" (American Thyroid Association (n.d.)). Typically, this can be diagnosed by determining if the thyroid volume is above average size, approximately $18.6 \mathrm{~mL}$ with upper limit being $23.1 \mathrm{~mL}$ (Hegedüs et al., 1983). It can be difficult to tell if the thyroid of an adolescent is enlarged with respect to the age, due to the constant growing process that characterizes this phase of human life.

\section{MATHEMATICAL DESCRIPTION AND SOLUTION APPROACH}

Data is obtained from the W.H.O. (World Health Organization, 1997) for the upper limits

of thyroid volume for males and females, ages 6-15, listed in Appendix A, Figure 1. This table is then split into two further tables by gender, shown in Appendix A, Figures $2 \mathrm{a}$ and $2 \mathrm{~b}$. 
The graph of each data set looks like portion of a parabola, therefore it is reasonable to model each graph by means of quadratic polynomials, denoted $f_{\text {male }}(x)$ and $f_{\text {female }}(x)$. To develop a model for each data set one could use the standard polynomial regression to find the best parabola, however we prefer an elementary approach based on averaging. First, we determine the rate of change between each of the data points, so to use it to compute the average rate of change. This process is roughly "equivalent" to approximating the first derivative for the modelling function. Then the average rate of change previously found is in turn averaged, giving the second derivative (in approximation) for the polynomial model. By direct inspection of the provided data, these values for the male set are 1.17778 and 1.23333 respectively, while for the female data set we obtain values of 0.225 and 0.075 respectively. All values of derivatives are included in Appendix A, Figures 3a and 3b.

Once the second derivative is determined, it is integrated to yield an equation for the first derivative. This equation is then set to the respective value for the first derivative, so to determine the integration constant, indicated by $c$. The average $c$ value is then taken, to obtain -1.18472 and 0.445833 for males and females respectively.

We use the following steps to obtain the suitable equation for the derivative of the polynomial function associated to the male set, $f^{\prime}$ male $(x)$ :

$$
\begin{gathered}
f^{\prime \prime}{ }_{\text {male }}(x)=0.225, \\
\int f^{\prime \prime}{ }_{\text {male }}(x) d x=f^{\prime}{ }_{\text {male }}(x)+\text { const }=0.225 x+c, \\
c=f_{\text {male }}^{\prime}(x)-0.225 x=-1.18472,
\end{gathered}
$$




$$
f_{\text {male }}^{\prime}(x)=0.225 x-1.18472 \text {. }
$$

With the equation of the first derivative and its constant determined, it is then integrated to yield the equation for the model of the gender under consideration with a new integration constant, $k$. The constant is solved for in a similar fashion, by taking the average $k$ for each age, with $f(x)$ being equal to the average upper limit of thyroid volume for the gender. The average upper limit of thyroid volume is 9.31 for males and 10.09 for females. The $k$ value is 8.4181 for males and 0.9650035 for females. Once the value for $k$ is determined, then the model for the expected upper limit of the thyroid volume can be determined as a function of age, $f(x)$. We use equation (1) to obtain the corresponding quadratic polynomial for males, $f_{\text {male }}(x)$ :

$$
\begin{gathered}
\int f_{\text {male }}^{\prime}(x) d x=f_{\text {male }}(x)+\text { const }=0.1125 x^{2}-1.18472 x+k, \\
k=9.31-\left(0.1125 x^{2}-1.18472 x\right)=8.4181 \\
f_{\text {male }}(x)=0.1125 x^{2}-1.18472 x+8.4181 .
\end{gathered}
$$

In a similar way we obtain the quadratic polynomial for females $f_{\text {female }}(x)$ :

$$
f_{\text {female }}(x)=0.0375 x^{2}+0.445833 x+0.9650035
$$

The additional equations for females are included in Appendix C. A brief account on the algorithm used to approximate a function in this manner is given in Appendix D. 


\section{DISCUSSION}

From the data obtained from the W.H.O., we determine that the upper limit of thyroid volume can be modeled by a second order polynomial equation that, in general, depends on the gender. For males, the function $f_{\text {male }}(x)$ is given in (2) while the function for females

$f_{\text {female }}(x)$ is given in (3), with $x$ being the age in years. As seen in Figure 4 of Appendix E and the graphs of Appendix F, both models accurately predict the values for the upper limit of the thyroid volume when compared to the data obtained by the W.H.O. While these models only apply, in principle, starting at an age of 6 years, they can be extended to an age of 18 years, as the predicted values fall near the upper limit of thyroid volume for adults of $23.1 \mathrm{~mL}$ (Hegedüs et al., 1983).

These models allow an easy way to determine if an adolescent has hyperthyroidism by comparing the volume of their thyroids usually obtained through an ultrasound procedure, to the predicted volume for their age. If the obtained volume is significantly higher than the volume predicted by the model, then it likely indicates a case of hyperthyroidism.

\section{CONCLUSIONS AND RECOMMENDATIONS}

From our analysis we conclude that one can indeed model the upper limit for the volume of the thyroid in an adolescent based on the age of the patient. This is different by gender, with the model for males being $f_{\text {male }}(x)=0.1125 x^{2}-1.18472 x+8.4181$ and the model for females being $f_{\text {female }}(x)=0.0375 x^{2}+0.445833 x+0.9650035$, with $x$ being the age of the patient in years. These models are based on data extrapolated from the W.H.O., which displays the upper limit of thyroid volume for ages 6-15 for males and females. These models can 
therefore only be reliably used beginning at age 6 . As seen in Figure 4 of Appendix E, these models can be extended to age 18 , as the results for both genders fit into the average age range for an adult thyroid.

It is recommended to use these models as an indicator of suspected hyperthyroidism, not as a definitive diagnosis. Other tests should be performed to verify any suspicion predicted by these models.

\section{NOMENCLATURE}

\begin{tabular}{|c|c|c|}
\hline Symbol & Representative of & Units \\
\hline $\mathrm{mL}$ & Volume & $\mathrm{mL}$ \\
\hline$x$ & Age & Years \\
\hline$f^{\prime}(x)$ & First Derivative & N/A \\
\hline$f^{\prime \prime}(x)$ & Second Derivative & N/A \\
\hline TV & Thyroid Volume & $\mathrm{mL}$ \\
\hline
\end{tabular}

\section{REFERENCES}

Hegedüs, L., Perrild, H., Poulsen, L. R., Andersen, J. R., Holm, B., Schnohr, P., Jensen, G., Hansen, J. M. (1983). The determination of thyroid volume by ultrasound and its relationship to body weight, age, and sex in normal subjects. The Journal of Clinical Endocrinology and Metabolism, 56(2), 260-263. https://doi.org/10.1210/jcem-56-2-260

American Thyroid Association. (n.d.). Hyperthyroidism. Retrieved from https://www.thyroid.org/hyperthyroidism/

World Health Organization. (1997). Recommended normative values for thyroid volume in children aged 6-15 years. World Health Organization \& International Council for Control 
Undergraduate Journal of Mathematical M odeling: One + Two, Vol. 9, Iss. 2 [2019], Art. 6

of Iodine Deficiency Disorders. Bulletin of the World Health Organization, 75(2), 95-97. https://www.ncbi.nlm.nih.gov/pmc/articles/PMC2486937/ 


\section{APPENDIX A: UPPER LIMITS OF THYROID VOLUME FROM THE W.H.O.}

Figure 1

\begin{tabular}{|r|r|r|}
\hline \multicolumn{1}{|c|}{ Upper Limit of Thyroid Volume (mL) } \\
\hline \multicolumn{1}{|c|}{ Age } & \multicolumn{1}{|c|}{ Male } & Female \\
\hline 6 & 5.4 & 5 \\
\hline 7 & 5.7 & 5.9 \\
\hline 8 & 6.1 & 6.9 \\
\hline 9 & 6.8 & 8 \\
\hline 10 & 7.8 & 10.4 \\
\hline 11 & 9 & 11.7 \\
\hline 12 & 10.4 & 13.1 \\
\hline 13 & 12 & 14.6 \\
\hline 14 & 13.9 & 16.1 \\
\hline 15 & 16 & \\
\hline \multicolumn{2}{|c}{ Values obtained from the W.H.O. } \\
\hline \multicolumn{3}{|c}{} \\
\hline
\end{tabular}

Figure 2a

\begin{tabular}{|c|c|}
\hline \multicolumn{2}{|c|}{ Upper Limit for Males (mL) } \\
\hline Age & TV \\
\hline 6 & 5.4 \\
\hline 7 & 5.7 \\
\hline 8 & 6.1 \\
\hline 9 & 6.8 \\
\hline 10 & 7.8 \\
\hline 11 & 9 \\
\hline 12 & 10.4 \\
\hline 13 & 12 \\
\hline 14 & 13.9 \\
\hline 15 & 16 \\
\hline Average & 9.31 \\
\hline Values obtained & e W.H.O. \\
\hline
\end{tabular}

Figure 2b

\begin{tabular}{|r|r|}
\hline \multicolumn{2}{|c|}{ Upper Limit for Females (mL) } \\
\hline Age & \multicolumn{1}{|c|}{ TV } \\
\hline 6 & 5 \\
\hline 7 & 6.9 \\
\hline 8 & 8 \\
\hline 9 & 9.2 \\
\hline 10 & 10.4 \\
\hline 11 & 11.7 \\
\hline 12 & 13.1 \\
\hline 13 & 14.6 \\
\hline 14 & 16.1 \\
\hline 15 & 10.09 \\
\hline \multicolumn{2}{|c|}{ Average } \\
\hline \multicolumn{2}{|c|}{ Values obtained from the W.H.O. } \\
\hline
\end{tabular}




\section{APPENDIX B: AVERAGE VALUE OF DERIVATIVES}

Figure 3a

\begin{tabular}{|l|r|r|}
\hline \multicolumn{3}{|c|}{ First Derivative } \\
\hline $\begin{array}{l}\text { Age } \\
\text { Range }\end{array}$ & $\begin{array}{l}\text { l' } \\
\text { Male }\end{array}$ & $\begin{array}{l}\text { l }(x) \\
\text { Female }\end{array}$ \\
\hline 7 to 6 & 0.3 & 0.9 \\
\hline 8 to 7 & 0.4 & 1 \\
\hline 9 to 8 & 0.7 & 1.1 \\
\hline 10 to 9 & 1 & 1.2 \\
\hline 11 to 10 & 1.2 & 1.2 \\
\hline 12 to 11 & 1.4 & 1.3 \\
\hline 13 to 12 & 1.6 & 1.4 \\
\hline 14 to 13 & 1.9 & 1.5 \\
\hline 15 to 14 & 2.1 & 1.5 \\
\hline Average & 1.177778 & 1.2333333 \\
\hline
\end{tabular}

Figure 3b

\begin{tabular}{|l|r|r|}
\hline \multicolumn{3}{|c|}{ Second Derivative } \\
\hline $\begin{array}{l}\text { Age } \\
\text { Range }\end{array}$ & $\begin{array}{l}f^{\prime \prime}(x) \\
\text { Male }\end{array}$ & \multicolumn{2}{l|}{$\begin{array}{l}f^{\prime \prime}(x) \\
\text { Female }\end{array}$} \\
\hline 8 to 7 & 0.1 & 0.1 \\
\hline 9 to 8 & 0.3 & 0.1 \\
\hline 10 to 9 & 0.3 & 0.1 \\
\hline 11 to 10 & 0.2 & 0 \\
\hline 12 to 11 & 0.2 & 0.1 \\
\hline 13 to 12 & 0.2 & 0.1 \\
\hline 14 to 13 & 0.3 & 0.1 \\
\hline 15 to 14 & 0.2 & 0 \\
\hline Average & 0.225 & 0.075 \\
\hline
\end{tabular}




\section{APPENDIX C: MODEL FOR THE UPPER LIMIT OF THYROID VOLUME IN}

\section{FEMALES}

$$
\begin{gathered}
f^{\prime \prime}{ }_{\text {female }}(x)=0.075 \\
\int f^{\prime \prime}{ }_{\text {female }}(x) d x=f^{\prime}{ }_{\text {female }}(x)+\text { const }=0.075 x+c, \\
c=f_{\text {female }}^{\prime}(x)-0.075 x \\
f^{\prime}{ }_{\text {female }}(x)=0.075 x+0.445833 \\
f_{\text {female }}^{\prime}(x) d x=f_{\text {female }}(x)+\text { const }=0.0375 x^{2}+0.445833 x+k \\
k=10.09-\left(0.0375 x^{2}+0.445833 x\right)=0.9650035 \\
f_{\text {female }}(x)=0.0375 x^{2}+0.445833 x+0.9650035
\end{gathered}
$$




\section{APPENDIX D: APPROXIMATION OF A FUNCTION}

1. Determine the value of the first derivative by finding an average rate of change value for the data set. This can be done by finding the individual rates of change between data points, then averaging them.

2. Determine the value of the second derivative by finding an average rate of change value for the previously found rate of changes. For example, to find the rate of change of the rate of change from groups 1 to 2 and groups 2 to 3 , subtract the rate of change from groups 1 to 2 from that of 2 to 3 . This process is then repeated, and the average is then taken.

3. Using this calculated value of the second derivative, integrate to find the formula of the first derivative.

4. Using the formula for the first derivative and the previously calculated value of the first derivative, solve for the average value of the constant, $c$, that appears when integrating. To do this, set the $x$ value of the equation to each respective $x$ value of the data set, then find the average of these values.

5. With the constant found, integrate again to get the approximated function, including a new constant, $k$.

6. Solve for $k$ by setting the approximated function equal to the average $y$ value of the data set. To do this, set the $x$ value of the equation to each respective $x$ value of the data set, then find the average of these values.

7. Substitute in this average value for $k$, and this is the approximated function for the data set. 
APPENDIX E: PROJECTED UPPER LIMIT OF THYROID VOLUME

Figure 4

\begin{tabular}{|r|r|r|}
\hline \multicolumn{3}{|c|}{ Upper Limit for Thyroid Volume (mL) } \\
\hline Age & Male & Female \\
\hline 6 & 5.3599 & 4.990001 \\
\hline 7 & 5.6377 & 5.923334 \\
\hline 8 & 6.1405 & 6.931667 \\
\hline 9 & 6.8683 & 8.015 \\
\hline 10 & 7.8211 & 9.173333 \\
\hline 11 & 8.9989 & 10.406666 \\
\hline 12 & 10.4017 & 11.714999 \\
\hline 13 & 12.0295 & 13.098332 \\
\hline 14 & 13.8823 & 14.556665 \\
\hline 15 & 15.9601 & 16.089998 \\
\hline 16 & 18.2629 & 17.698331 \\
\hline 17 & 20.7907 & 19.381664 \\
\hline 18 & 23.5435 & 21.139997 \\
\hline
\end{tabular}




\section{APPENDIX F: GRAPHICAL REPRESENTATION}
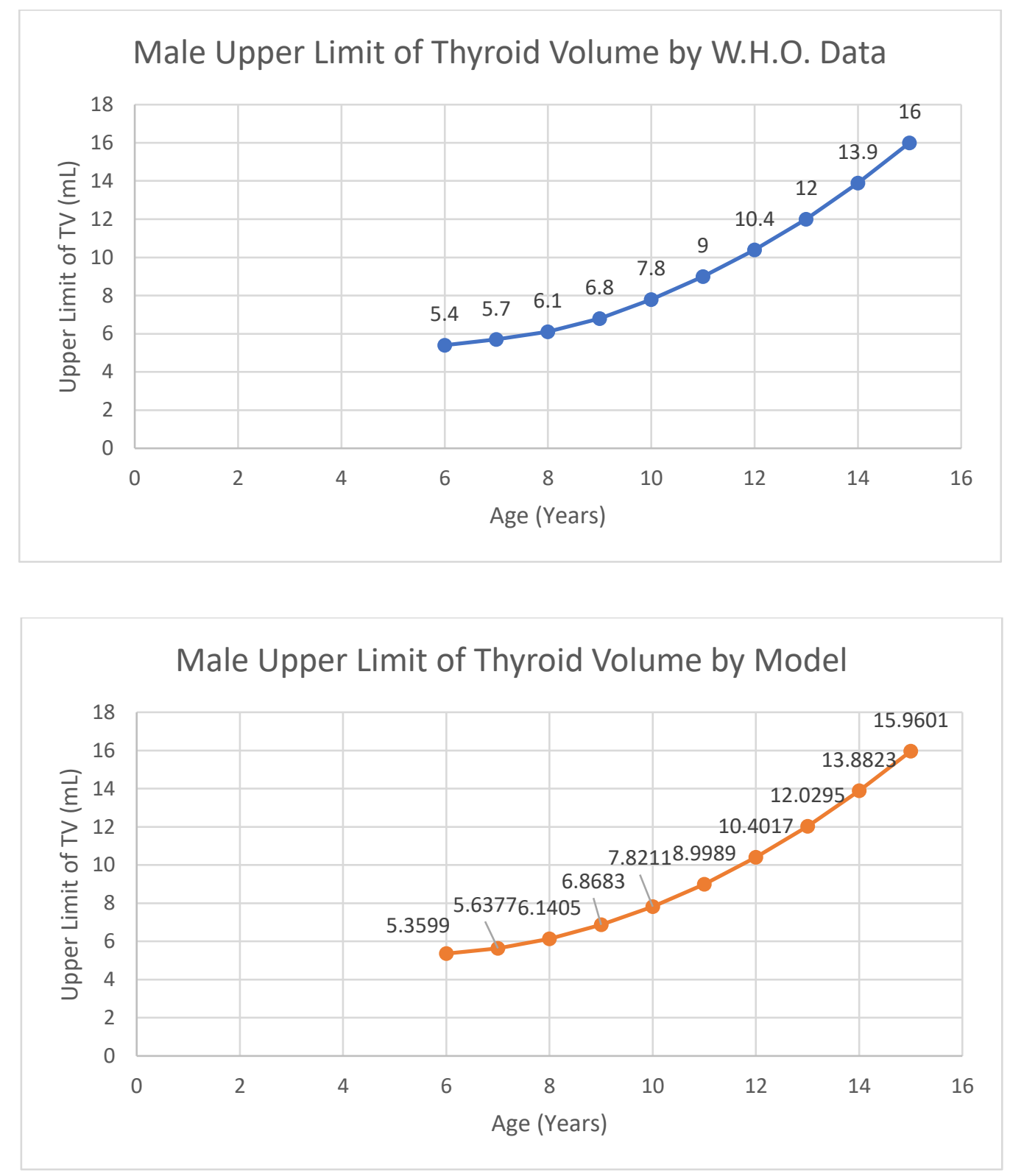

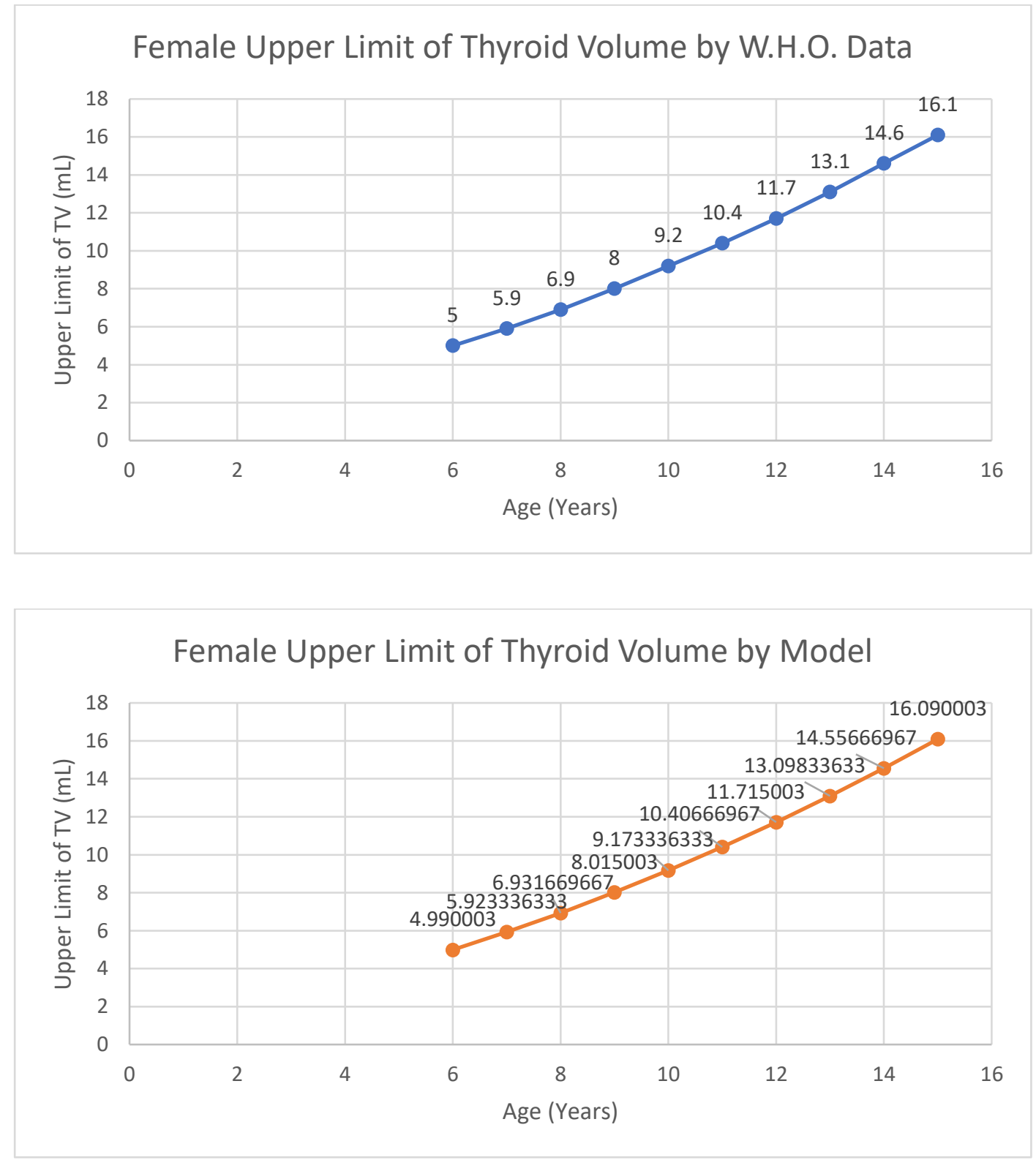